\title{
Effect of Weight Ball Throw Training on Weight Shifting of Lower Body, Head Speed of Club, and Driving Distance of Amateur Golfers
}

\author{
Woo-Jin Choi, PT • Tack-Hoon Kim, PT, PhD ${ }^{1 \dagger} \cdot$ Dong-Sik Oh, PT, MS \\ Dept. of Physical Therapy, Shinnae Sungmo Orthopedics Clinic \\ ${ }^{1}$ Dept. of Physical Therapy, Hanseo University
}

Received: July 24, 2017 / Revised: July 28, 2017 / Accepted: August 7, 2017

(C) 2017 J Korean Soc Phys Med

\begin{abstract}
| Abstract |
PURPOSE: To determine the effect of weight ball throw training as a preparatory exercise before golf practice for 8 weeks on back muscle strength, weight shifting of lower body, head speed of club, and driving distance of amateur golfers.

METHODS: A total of 18 subjects were randomly assigned to the experimental group $(n=9)$ and the control group $(n=9)$, respectively. For the experimental group, Weight ball throw training was provided to the height of waist and shoulder similar to golf swing with the following schedule: $3 \mathrm{~kg}$ weight ball throw training from the first week to the 4 th week; $5 \mathrm{~kg}$ weight ball throw training from the 5 th week to the 8 th week. Before and after 8 weeks of training, back muscle strength, weight shifting of lower body, head speed of club, and driving distance of subjects in the two groups were measured.
\end{abstract}

RESULTS: The experimental group showed significant differences in rotational back extension torque, weight shifting of lower body, head speed of club, and driving

† Corresponding Author : tack@hanseo.ac.kr

This is an Open Access article distributed under the terms of the Creative Commons Attribution Non-Commercial License (http://creativecommons.org/licenses/by-nc/3.0) which permits unrestricted non-commercial use, distribution, and reproduction in any medium, provided the original work is properly cited. distance during golf swing $(\mathrm{p}<.05)$. However, the control group only showed significant difference in driving distance during golf swing $(\mathrm{p}<.05)$. Back extension torque, weight shifting of lower body, and head speed of club showed significant differences between the two groups during golf swing $(\mathrm{p}<.05)$.

CONCLUSION: Weight ball throw training can positively change rotational back muscle strength, weight shifting of lower body, head speed of club, and driving distance of amateur golfers. Therefore, it might be used as an effective warming up exercise for amateur golfers.

Key Words: Driving distance, Golf, Head speed, Weight ball, Weight shift

\section{Introduction}

In golf swing, efficient swing posture and weight shift are very important. A good shot by a good swing should have speed, accuracy, and consistency. These three factors are closely related to each other and play a complementary role (So, 1997). Increased driving distance is one of the most important factors in winning a golf competition (Hetu et al., 1998). The most important factor that affects the driving distance is head speed of the club (Fletcher 
and Hartwell, 2004). To improve the speed of club head, the lower body of a golfer requires stable weight shift and muscle strength (Park, 2000). Balance in the standing position is closely related to the ability to move weight on one leg (Ko and Lee, 2017). Effective and proper weight transfer is essential to maintaining a good balance by naturally twisting the upper body and delivering the maximum momentum to the ball (Zumerchik, 2010).

To increase muscle strength and power by making muscle contraction and relaxation momentarily, exchanging and throwing a weight ball has been used because it can cause muscle contraction with a load equal to ground reaction by gravitational acceleration (Woo, 2001). The momentum with a throwing or striking motion can be maximized when it is transmitted in the same direction as the direction the projectile is aiming. Proper weight shifting is required to produce a large ground reaction force in order to transmit the projectile farther (Hume, 2005).

Read et al. (2013) have reported that the most effective way to increase club head speed is by squat jumping and side throwing training of weight ball during various plyometric movements. Through this training, various lower body weight movements are changed, thus increasing the club head speed. Throwing training of weight ball is a combination of weight training. It is included in plyometric training because it can improve driving distance and head speed of golf players (Park and Jung, 2007; Fletcher and Hartwell, 2004). In a training study using weight balls for ball games such as handball, baseball, and softball, Szymanski et al. (2010) have conducted a throwing training to male and female baseball by changing the weight of weight ball 3 days a week for 8 weeks. Their results showed that the swing speed of bat and the velocity of the ball hit on the bat were both increased regardless of ball type. Ignjatovic et al. (2012) have reported that the use of weight ball in female handball players has resulted in significant increase in upper body strength and lower body mobility compared to the control group.

Based on the previous studies in the ball game, the objective of this study was to determine the effect of weight ball throw training on rotation back extension torque, weight shift of the lower body, head speed of the club, and driving distance of amateur golfers.

\section{Methods}

\section{Subjects}

The subjects were right-handed amateur golfers with a handicap 15 or more. They had less than 5 years of golf experience in S golf driving range in Seoul. A total of 18 subjects were randomly assigned to the experimental group $(\mathrm{n}=9)$ and the control group $(\mathrm{n}=9)$, respectively. They were selected as normal cognitive abilities without orthopedic problems. After explaining the purpose of this study to participants, they agreed to be enrolled in the experiment.

\section{Experimental methods}

In this study, subjects in the experimental group were given 20 minutes of weight ball throw training as preparatory exercise before golf practice. Subjects in the control group practiced golf for the same time without training.

Rotational back extension torque $(\mathrm{kg})$, weight shifting of lower body (\%), head speed of club ( $\mathrm{m} / \mathrm{s})$, and driving distance $(\mathrm{m})$ were measured before and after 8 weeks of training.

\section{1) Weight ball throw training}

In the experimental group, the subjects held the weight ball with both hands and stood straight. Then, threw the weight ball from one side of the waist to the other side of the shoulder, like a golf swing motion. Training was carried out four to five times a minute, allowing weight 


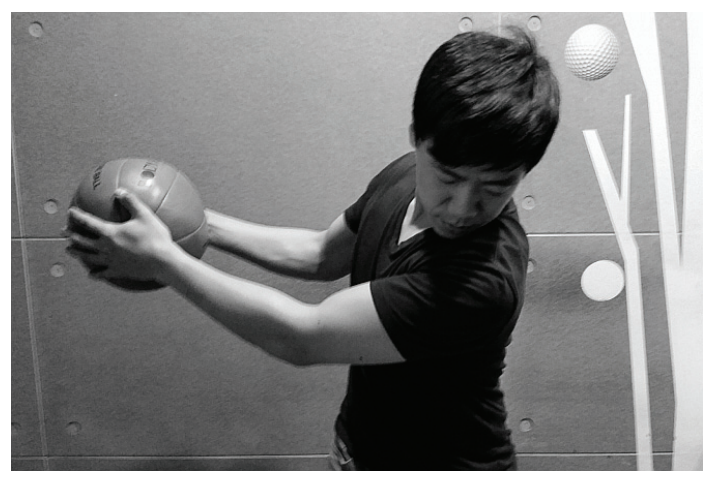

Fig. 1. Weight ball throw training

shift to the right foot before throwing, and weight shift to the left foot while throwing. To increase the effect of weight ball throw training, the shape of the golf swing was formed (Fig. 1). Waist height was formed in the shape of a $2 / 4$ swing of golf swing while shoulder height was formed in the shape of a $3 / 4$ swing. $3 \mathrm{~kg}$ of weight ball was lifted up and thrown to the waist height for the first two weeks ( $1^{\text {st }}$ and $2^{\text {nd }}$ week). It was then shifted to shoulder height for the next two weeks ( $3^{\text {rd }}$ and $4^{\text {th }}$ week). Then $5 \mathrm{~kg}$ of weight ball was lifted up to the waist height for two weeks ( $5^{\text {th }}$ and $6^{\text {th }}$ week). It was then shifted to the shoulder height for the last two weeks ( $7^{\text {th }}$ and $8^{\text {th }}$ week) before golf practice.

\section{Measurement methods and tools}

\section{1) Rotational back extension torque}

Rotational back extension torque was measured using a back force meter (BACK-D, T.K.K.5102, TAKEI, Japan). Subjects in both experimental group and control group were measured before and after eight weeks of golf practice. Regarding the measurement method, the height of the back force handle was adjusted so that the angle between the back force system and the upper body was $30^{\circ}$ after tilting the upper body and grasping handle on the back force system with legs spreading about $15 \mathrm{~cm}$ to measure back force.
2) Weight shifting of lower body, head speed of club, and driving distance

Head speed of club, driving distance, and weight shifting of lower body were measured using X-balance, a screen golf device. The X-balance (2CH X-BALANCE, RD-TEK, Korea) was used to analyze weight shift of legs loaded on the ground during golf swing as a percentage (\%). It could simultaneously measure head speed of club $(\mathrm{m} / \mathrm{s})$ and driving distance $(\mathrm{m})$ with an optical sensor. Head speed, driving distance, and weight shifting were calculated as the average of three performances minus the highest and lowest points of five attempts of participant using 7 iron club. Regarding weight shifting of lower body, the percentage of body weight (\%) loaded on the left foot at the moment of hitting the golf ball was measured by subtracting the percentage of body weight loaded on the left foot from the peak of backswing.

\section{Data analysis}

SPSS ver. 21.0 was used for all data analyses. Mean and standard deviation of each measurement item were calculated for each group. Kolmogorov-Smirnov test was used to determine if there were significant differences in back extension torque, weight shifting of lower body, and head speed of club, and driving distance before and after training within the two groups. Independent $t$-test was used to compare results between the two groups. Statistical significance was set at $\mathrm{p}<.05$.

\section{Results}

\section{General characteristics of subjects}

Subjects were randomly assigned to 9 experimental and control groups, respectively. There was no significant difference in general characteristics between the two groups $(\mathrm{p}>.05)$ (Table 1). 
Table 1. General characteristics of subjects $(\mathrm{N}=18)$

\begin{tabular}{ccc}
\hline & Experimental group $(\mathrm{n}=9)$ & Control group $(\mathrm{n}=9)$ \\
\hline Age & $36.22 \pm 5.91^{\mathrm{a}}$ & $35.83 \pm 9.01$ \\
Height $(\mathrm{cm})$ & $174.4 \pm 5.72$ & $173.02 \pm 6.54$ \\
Weight $(\mathrm{kg})$ & $75.03 \pm 10.71$ & $72.32 \pm 12.81$ \\
\hline
\end{tabular}

${ }^{\mathrm{a}}$ Mean \pm Standard deviation

2. Comparison of rotational back extension torque between the two groups

Rotational back extension torque was also significantly increased from $134.11 \pm 32.24 \mathrm{~kg}$ before training to 152.22 $\pm 36.95 \mathrm{~kg}$ after training in the experimental group $(\mathrm{p}<.05)$ (Table 2). However, there was no significant difference in rotational back extension torque in the control group during golf swing $(p>.05)$. There was significant difference in rotational back extension torque after golf practice between the two groups $(p<.05)$.
3. Comparison of weight shifting of lower body between the two groups

Weight shifting of lower body in experimental group was significantly increased from $33.00 \pm 6.40 \%$ before training to $44.33 \pm 5.31 \%$ after training $(\mathrm{p}<.05)$ (Table 2$)$. However, there was no significant difference in weight shifting of lower body in the control group during golf swing $(\mathrm{p}>.05)$. There was significant difference in weight shifting of lower body between the two groups during golf swing $(\mathrm{p}<.05)$.

Table 2. Comparison of WSLB, HSC, DD between the two groups

\begin{tabular}{|c|c|c|c|c|c|}
\hline & & Experimental Group $(\mathrm{n}=9)$ & Control Group (n=9) & $\mathrm{t}$ & $\mathrm{p}$ \\
\hline \multirow{4}{*}{ RBET } & Pre $(k g)$ & $134.11 \pm 32.24^{\mathrm{a}}$ & $129.11 \pm 26.41$ & .86 & .42 \\
\hline & Post (kg) & $152.22 \pm 36.95$ & $131.11 \pm 26.10$ & 3.95 & $.00 *$ \\
\hline & $\mathrm{t}$ & -4.29 & -.60 & & \\
\hline & $\mathrm{p}$ & $.00 *$ & .57 & & \\
\hline \multirow{4}{*}{ WSLB } & Pre $(\%)$ & $33.00 \pm 6.40$ & $33.44 \pm 9.32$ & -.17 & .87 \\
\hline & Post $(\%)$ & $44.33 \pm 5.31$ & $34.44 \pm 9.19$ & 3.47 & $.01 *$ \\
\hline & $\mathrm{t}$ & -6.51 & -1.90 & & \\
\hline & $\mathrm{p}$ & $.00 *$ & .09 & & \\
\hline \multirow{4}{*}{ HSC } & Pre $(\mathrm{m} / \mathrm{s})$ & $37.66 \pm 3.74$ & $38.66 \pm 5.40$ & -.74 & .48 \\
\hline & Post $(\mathrm{m} / \mathrm{s})$ & $43.66 \pm 4.03$ & $39.22 \pm 4.96$ & 4.16 & $.00^{*}$ \\
\hline & $\mathrm{t}$ & -8.49 & -1.47 & & \\
\hline & $\mathrm{p}$ & $.00 *$ & .18 & & \\
\hline \multirow{4}{*}{ DD } & Pre $(\mathrm{m})$ & $126.88 \pm 10.98$ & $128.55 \pm 13.12$ & -0.55 & .60 \\
\hline & Post (m) & $135.88 \pm 10.85$ & $130.44 \pm 13.33$ & 1.94 & .09 \\
\hline & $\mathrm{t}$ & -7.88 & -3.90 & & \\
\hline & $\mathrm{p}$ & $.00 *$ & $.01 *$ & & \\
\hline
\end{tabular}

${ }^{\mathrm{a}}$ Mean \pm Standard deviation, $* \mathrm{p}<.05$

RBET; rotational back extension torque, WSLB; weight shifting of lower body, HSC; head speed of club, DD; driving distance 


\section{Comparison of head speed of club between} the two groups

Head speed of club in experimental group was significantly increased from $37.66 \pm 3.74 \mathrm{~m} / \mathrm{s}$ before training to $43.66 \pm 4.03 \mathrm{~m} / \mathrm{s}$ after training $(\mathrm{p}<.05)$ (Table 2). However, there was no significant difference in head speed of club in the control group during golf swing ( $>$.05). There was significant difference in head speed of club between the two groups during golf swing $(\mathrm{p}<.05)$.

\section{Comparison of driving distance between the two groups}

In both groups, driving distance was significantly increased during golf swing $(\mathrm{p}<.05)$ (Table 2$)$. In the experimental group, driving distance was significantly increased from $126.88 \pm 10.98 \mathrm{~m}$ before training to 135.88 $\pm 10.85 \mathrm{~m}$ after training $(\mathrm{p}<.05)$. In the control group, driving distance was also significantly increased from $128.55 \pm 13.12 \mathrm{~m}$ to $130.44 \pm 13.33 \mathrm{~m}(\mathrm{p}<.05)$. There was no significant difference in driving distance between the two groups before or after training ( $>$.05).

\section{Discussion}

Exchanging and throwing a medicine ball has been found to be an effective way to improve muscle strength and power (Woo, 2001). In the present study, we found that weight ball throw training increases the trunk muscle activity of the athlete. However, there is little research to find out whether such training actually occurs in non-athletes. Therefore, the purpose of this study was to investigate the effects of weight ball throw training on weight shifting of lower body, head speed of club and driving distance of amateur golfers.

In this study, weight ball throw training significantly increased rotational back extension torque of subjects in the experimental group from $134.11 \pm 32.24 \mathrm{~kg}$ before training to $152.22 \pm 36.95 \mathrm{~kg}$ after training.
Ikeda et al. (2009) have reported that muscle activity is increased for trunk muscles, especially external oblique muscle, when throw training is provided by changing throwing distance of 2, 4, and $6 \mathrm{~kg}$ of weight balls. Gordon et al. (2009) have suggested that repeatedly throwing 3 $\mathrm{kg}$ weight ball with upper body rotation as warming up exercise with pre-exercises can increase trunk rotation power of male golfers. In golf swing, the core, abdomen, and waist are main body parts that induce a great deal of power in exerting a force called power zone in the body. Muscles around the lumbosacral joint play an important role in maintaining functional stability (Akuthota and Nadler, 2004). For this reason, it is necessary to strengthen the core part in order to improve the amount of trunk rotation with strong impact, thus improving golf performance. Weakness and imbalance of the lower back muscle are important factors for golfers to restrict performance and activities (Delisa, 1988; Foster and Fulton, 1991). Cole (2008) has reported that golfers with poor performance in the upper body muscles tend to have slightly muscle strength around the lower back.

Jorgensen (1999) has reported a numerically increased club head speed of $8.8 \%$ after proper weight shifting compared to no weight shift at all. Hong (2005) has studied the pattern of weight shift. To improve driving distance of golf swing, amateur golfers have to take weight shift to the opposite side and load weight inside the foot in the backswing top during speeding up swing speed by about $20 \%$. Queen et al. (2013) have emphasized the importance of horizontal movement of the pelvis by observing the amount of weight and timing applied to the two feet during a golf swing of golfers with different handicap. In their study, the difference between amateur golfers and professional golfers was classified according to weight distribution of the two feet at impact. Plagenhoef (1983) has found that weight is shifted by $75 \%$ of total movement during impact. Kwon (1999) has reported that $35.2 \%$ of weight on the left foot in the backswing and $80 \%$ of weight on the left 
foot at impact are loaded during golf swing.

In the control group of our study, driving distance was significantly increased from $128.55 \pm 13.12 \mathrm{~m}$ to $130.44 \pm$ $13.33 \mathrm{~m}$. This seems to have improved the swing ability as a result of the 8 weeks of practice. There was no statistically significant difference in driving distance between the two groups after practice. However, weight ball throw training increased the driving distance by $4 \%$ (135.88 $10.85 \mathrm{~m}$ in the experimental group after training and practice vs. $130.44 \pm 13.33 \mathrm{~m}$ in the control group after practice).

Therefore, the weight ball throw training showed an improvement in the weight shifting of lower body. This has a positive effect on golf performance, and I think it improved not only head speed but also distance.

This study has some limitations. First, this study did not control individual training or everyday life of subjects. Whether results of this study could be applied to professional golfers was not determined. In addition, there might be prejudice because the effect of learning might affect measurement value. Therefore, further studies are needed by including more golfers as subjects by study muscles during weight ball throw training and the duration of the effectiveness from such training.

\section{Conclusion}

Weight ball throw training can positively change rotational back muscle strength, weight shifting of lower body, head speed of club, and driving distance of amateur golfer. Therefore, it might be used as an effective training method as a warming up exercise before golf practice.

\section{References}

Akuthota V, Nadler SF. Core strengthening. Arch Phys Med Rehabil. 2004;85(3):86-92.
Burdett RG, Vanswearinger J. Reliability of isokinetic muscle endurance test. Sport Phys. 1987;8:484-8.

Cole MH, Grimshaw PN. Electromyography of the trunk and abdominal muscles in golfers with and without low back pain. J Sci Med Sport. 2008;11(2):174-81.

Delisa JA. Rehabilitation medicine: Principles and Practice. USA. Lippincott Williams \& Wilkins. 1988.

Fletcher IM, Hartwell M. Effect of an 8-week combined weights and plyometrics training program on golf drive performance. J Strength Cond Res. 2004;18(1):59-62.

Foster DN, Fulton MN. Back pain and the exercise prescription. Clin Sports Med. 1991;10(1):197-209.

Gordon BS, Moir GL, Davis SE. An investigation into the relationship of flexibility, power, and strength to club head speed in male golfers. JSCR. 2009;23(5): 1606-10.

Hetu FE, Christie CA, Faigenbaum AD. Effects of conditioning on physical fitness and club head speed in mature golfers. Percept Mot Skills. 1998;86:811-5.

Hong G. The research of body weight movement in golf swing. Doctor's Degree. Kyung Hee University. 2005.

Hume PA, Keogh J, Reid D. The role of biomechanics in maximising distance and accuracy of golf shots. Division of Sport and Recreation. 2005;35(5):429-49. Ignjatovic AM, Markovic ZM, Radovanovic DS. Effects of 12-week medicine ball training on muscle strength and power in young female handball players. J Strength Cond Res. 2012;26(8):2166-73.

Ikeda Y, Miyatsuji K, Kawabata K. Analysis of trunk muscle activity in the Side medicine-ball throw. JSCR. 2009;23(8):2231-40.

Jorgensen TP. The physics of golf. USA. Springer Science \& Business Media. 1999.

Ko YJ, Lee HS. The Effect of Weight-shift Training with Hula Hoop on Weight Shift Change and Gait in Stroke Patients: A Cross - Sectional Pilot Study. J Korean Soc Phys Med. 2017;12(1):9-14.

Kwon EJ. Biomechanics analysis of ground reaction force 
and muscle moment on golf swing. Doctor's Degree. Suwon University. 1999.

Park WY. The variability of physical fitness related physiological variables during four days of golf round. Doctor's Degree. Dankook University. 2000.

Park WY, Jung SW. The Effect of Physical Training on Fitness and Driver Head Speed, Long Distance in Women Golfers. KSR. 2007;18(2):647-54.

Plagenhoef S. Golf research projects. ISBS-Conference Proceedings Archive. 1983;1(1):167-89.

Queen RM, Butler RJ, Dai B, et al. Difference in peak weight transfer and timing based on golf handicap. JSCR. 2013;27(9):2481-6.

Read PJ, Lloyd RS, De SC. Relationships between field-based measures of strength and power and golf club head speed. JSCR. 2013;27(10):2708-13.

So JM. A Kinematic Analysis on Golf Driver Swing for the physique. The Research Institute of Education KonKuk University. Teachers and Education. 1997;21: $237-46$

Szymanski D, McHenry SP, Blankenship TM, et al. Effect of medicine ball training on bat swing and batted-ball velocities of novice participants. JSCR. 2010;24:1.

Woo HJ. The Effect of Plyometric Training on Speed Skate. Master's Degree. Hanyang University. 2001.

Zumerchik J. Newton on the tee: A good walk through the science of golf. USA. Simon \& Schuster. 2010. 
